Obere Extremität 2020 • 15:307-309 https://doi.org/10.1007/s11678-020-00602-z Received: 4 June 2020

Accepted: 28 August 2020

Published online: 12 October 2020

(c) The Author(s) 2020

\section{Video online}

The online version of this article (https://doi. org/10.1007/s11678-020-00602-z) contains the video "Doppelplatten-Osteosynthese zur Versorgung proximaler Ulnafrakturen". You will find the video at the end of the article as "Supplementary material." Video by courtesy of $\odot$ www.fame-forum.de.

\section{Background}

Olecranon fractures account for a significant part of all fractures in the area of the upper extremity in adults, with a frequency of approximately $10 \%$. Osteosynthesis is the treatment of choice for proximal ulnar fractures in most cases. The goal of osteosynthesis is to restore the anatomical congruence of the elbow joint and the integrity of the extensor apparatus in order to achieve early functional, physiotherapeutic aftercare.

Simple transverse fractures proximal to the olecranon midline can potentially be stabilized by tension-band osteosynthesis. However, if there are oblique fractures or the fracture gap exceeds the apex of the olecranon fossa (• Fig. 1), the tension band can no longer trigger sufficient compression and instead causes a redirection to shear forces. The result can be a shortening of the olecranon fork. Low-profile plates in combination with lag screws represent an excellent modality for achieving stable joint congruence, in more complex fractures in particular. In addition to the use of dorsal lowprofile plates, double-plate osteosynthesis in lateral and medial positioning is an established procedure in our hospital and offers several advantages. Thanks to

\author{
Nadine Ott ${ }^{1}$ - Michael Hackl ${ }^{1}$ William Geissler ${ }^{2}$ Lars P. Müller ${ }^{1}$ \\ ' Department of Trauma, Hand and Elbow Surgery, University Hospital of Cologne, Cologne, Germany \\ ${ }^{2}$ Division of Hand and Upper Extremity Surgery, Department of Orthopaedic Surgery and Rehabilitation, \\ University of Mississippi Medical Center, Jackson, USA
}

\title{
Double-plate osteosynthesis for proximal ulnar fractures
}

the anatomical plate design and the lateral and medial positioning, it not only allows for anchoring with angle-stable screw placement, but also for bicortical and orthogonal screw connection with respect to the pulling forces of the triceps brachii muscle $[2,5]$.

\section{Surgical technique}

Preoperative preparation and positioning of the patient The instruments should be checked for completeness. In addition to the basic instruments for osteosynthesis, including pointed reduction forceps and 2.0-mm Kirschner wires, flat profile plate instruments (Medartis; APTUS Ellenbogen, Basel, Switzerland) are required. Our hospital prefers to perform the surgery with the patient in the prone position whereby the affected arm is suspended from a mini table and is flexed at $90^{\circ}$ at the elbow joint. The use of an upper-arm tourniquet is optional. A single-shot antibiotic should already be administered at the start taking into consideration possible allergies.

\section{Surgical steps}

The approach is made proximal to the olecranon tip, starting as a dorsal skin incision above the elbow joint-the olecranon is bypassed radially here in our procedure - and follows distal to the dorsal ulnar edge. In general, the approach should be kept as small as possible; It can be extended at any time for the treatment of potential concomitant osseous injuries. These include, for example, injuries to the radial head or the coronoid process as well as to the medial or lateral collateral ligament.

Under hemostasis, especially in the area of the olecranon bursa, a sharp preparation follows on the dorsal ulnar edge with the ulnar and radial muscles pushed aside. Preparation of so-called full-thickness flaps is recommended here to maintain the blood flow. Protective display of the ulnar nerve is carried out regularly in our procedure, not only with complex fracture forms. After surgically uncovering the fracture, the gap is cleaned of the impacted periosteum, fracture hematoma, and cartilage bone flakes. With simple fractures, it is usually sufficient to assess the reduction result on the dorsal cortex alignment. With intra-articular multiple fragmentation, however, it may be helpful to open up the fracture gap and reduce the fragments anatomically. A dorsal auxiliary hole, $4-5 \mathrm{~cm}$ distal to the fracture, is useful for fixing the reduction forceps to the ulnar shaft. The result of the reduction can be fixed in place temporarily with one or two Kirschner wires. However, the Kirschner wires should not pass into the proximal radioulnar joint. Narrowing of the trochlear notch can cause an incongruity of the humeroulnar joint space and should be avoided. The two anatomically preformed plates can then be positioned on the side of the olecranon.

After satisfactory positioning, it is recommended that drilling and screw placement (2.8-mm screws) begin in the distal part of the oblong hole. This allows for distalization of the plate with compression at the fracture gap. It is often helpful to approach the tendon incision of the triceps brachii muscle longitudinally to the 

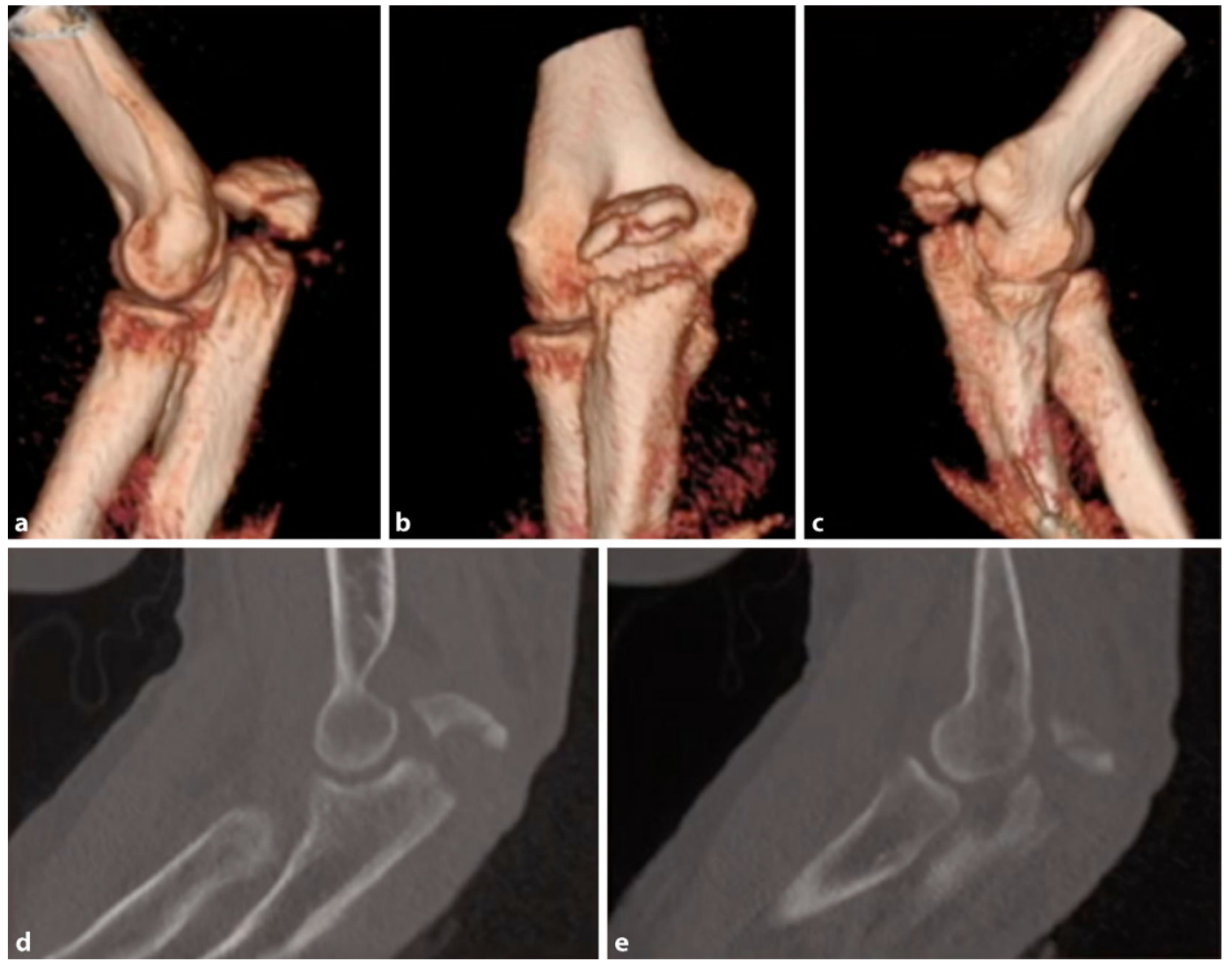

Fig. $1<$ Computed tomography diagnostics with three-dimensional reconstruction of a proximal ulnar fracture, type Mayo IIA. a-c three-dimensional reconstruction, $d$-e sagitall view of the elbow

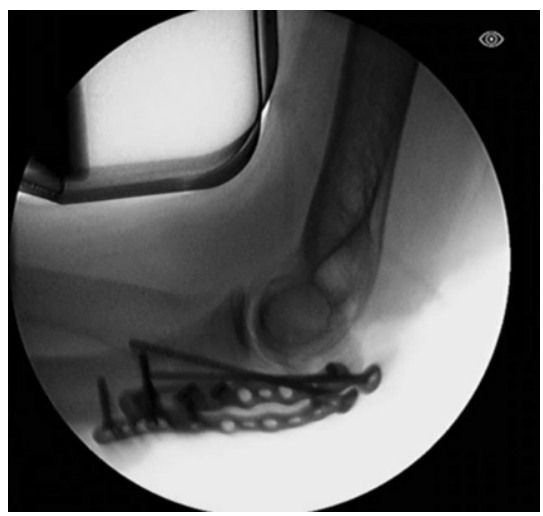

Fig. $2 \Delta$ Monitoring under image intensifier to assess the anatomical congruence of the proximal radioulnar and the humeroulnar joint; exclusion of an intra-articular screw position

triceps fibers at the level of the proximal end of the plate so that the proximal end of the plate can be inserted and recessed beneath it. The most proximal plate hole is used, after the plate has been fixed to the shaft. If there is no relevant debris zone or defect section, the proximal screw should be placed below the subchondral layer of the olecranon and should run bicortically through the coronoid base. By inserting a partial thread screw, the fracture gap can be compressed. Before compressing the fracture, however, the second plate should be placed in an analogous manner, and the distal screws in the elongated hole should be loosened again. This is a way to achieve sufficient and extensive compression of the fracture gap. The proximal and distal fragments should-if possible-be held by at least two to three screws each per plate. Care should be taken that the distal screws of the two plates do not end at the same height in the shaft area [3]. Caution should be exercised with metaphyseal screws inserted from ulnar to radial direction. They can affect the proximal radioulnar joint, and their position and length should be examined critically. With osteoporotic fractures in particular, an additive "off-loading triceps suture" can be useful. Securing of the ulnar nerve is essential here. The triceps tendon is reinforced $1-2 \mathrm{~cm}$ proximal to its insertion point by a suture, for example, with the help of one or two FiberTapes (Arthrex, Naples, FL, USA), diverted on the inserted plates via free holes or transosseously and knotted over the ulnar shaft. The objective is to reduce the tension on the triceps tendon on the proximal fragment [4].

The image intensifier is then checked in two exact levels in conclusion. In addition to assessing the anatomical joint congruence of the proximal radioulnar and humeroulnar joint, the exclusion of an intra-articular screw position is essential (• Fig. 2). After the desired result is achieved with reduction and the implant is positioned correctly, the wound is closed layer by layer; bulging knots should be avoided due to possible softtissue irritation. By positioning the plates medially and laterally to the dorsal ulnar edge, the fascia usually completely closes over the plate.

\section{Aftercare}

An immobilizing plaster splint can be useful in critical soft-tissue situations until it can be established that the wound is healing. In general, however, the focus is on early functional, physiotherapeutic exercise of the elbow joint. Full loading is usually permitted after 3 months when 
bone consolidation can be seen radiologically.

\section{Discussion}

Double-plate osteosynthesis allows for safe and stable fracture treatment and enables simultaneous treatment of possible concomitant injuries through the extension of the access point. The two subfascial plates with polyaxial angle-stable screws also make it possible for even small fragments to be screwed together in a manner stable for mobilization [5]. We see clear advantages in the clinical application due to the anatomical precontouring as well as the easy and precise adaptability. In our experience, doubleplate osteosynthesis leads to soft-tissue irritation less frequently, compared with bulky dorsal plates. However, to date there is no evidence in the literature of a reduced rate of metal removal compared with tension-band osteosynthesis or prominent dorsal plates [1].

In summary, double-plate osteosynthesis has become established as the surgical standard for proximal ulnar fractures in our hospital, while tensionband osteosynthesis still plays a subordinate role. One limitation for the use of the double-plate osteosynthesis with low-profile plates described here is an expansion of the fracture into the metaphysis or the proximal ulnar shaft. In such cases, the use of long dorsal plates (usually $3.5-\mathrm{mm}$ systems) is preferable.

\section{Practical conclusion \\ - Double-plate osteosynthesis has become established for the treatment of complex fractures of the proximal ulna. \\ - At our hospital, double-plate os- teosynthesis has largely replaced tension-band osteosynthesis. \\ - The simultaneous treatment of possible concomitant injuries and the fact that soft-tissue irritation is rarely observed represent a decisive advantage.}

\section{Corresponding address}

\section{Nadine Ott}

Department of Trauma, Hand and Elbow Surgery, University Hospital of Cologne Kerpener Str. 62, 50937 Cologne, Germany Nadine.ott@uk-koeln.de

Funding. Open Access funding provided by Projekt DEAL.

\section{Compliance with ethical guidelines}

Conflict of interest. M. Hackl discloses that he received support for research projects from Medartis and Arthrex. N. Ott, W. Geissler and L.P. Müller declare that they have no competing interests.

This article does not involve studies on humans or animals carried out by the authors.

Open Access. This article is licensed under a Creative Commons Attribution 4.0 International License, which permits use, sharing, adaptation, distribution and reproduction in any medium or format, as long as you give appropriate credit to the original author(s) and the source, provide a link to the Creative Commons licence, and indicate if changes were made. The images or other third party material in this article are included in the article's Creative Commons licence, unless indicated otherwise in a credit line to the material. If material is not included in the article's Creative Commons licence and your intended use is not permitted by statutory regulation or exceeds the permitted use, you will need to obtain permission directly from the copyright holder. To view a copy of this licence, visit http://creativecommons.org/licenses/by/4.0/.

\section{References}

1. Ellwein $A$, Lill H, WarnhoffM, Hackl M, Wegmann K, Müller LP, Gramlich Y, Hoffmann R, Klug A (2020) A can low-profile double-plate osteosynthesis for olecranon fractures reduce implant removal? A retrospective multicenter study. J Shoulder Elbow Surg 29(6):1275-1281. https://doi.org/10.1016/j. jse.2020.01.091

2. Hackl M, Mayer K, Weber M, Staat M, van Riet R, Burkhart KJ et al (2017) Plate osteosynthesis of proximal ulna fractures-A biomechanical micromotion analysis. J Hand Surg Am 42(834):e1-e7

3. Hackl M, Wegmann K, Taibah S, Burkhart KJ, Scaal M, Müller LP (2015) Peri-implant failure in dual plating of the distal humerus-A biomechanical analysis with regard to screw and plate positioning. Injury 46(11):2142-2145. https://doi. org/10.1016/j.injury.2015.08.015

4. Izzi J, Athwal GS (2012) An offloading triceps suture for augmentation of plate fixation in comminuted osteoporotic fractures of the olecranon. J Orthop Trauma 26:59-61

5. Ries C, Wegmann K, Meffert RH, Muller LP, Burkhart KJ (2015) Double-plate osteosynthesis of the proximal ulna. Oper Orthop Traumatol 27:342-356 